\title{
THE BREEDING BIRD SURVEY IN CANADA
}

\author{
by A. J. Erskine, Canadian Wildlife Service, Ottawa
}

The Breeding Bird Survey is a cooperative attempt by volunteer and professional bird students to detect and measure year-to-year changes in numbers of birds across North America. Man's activities are changing his environment at an ever increasing rate, in ways which may be expected to affect bird numbers. In recent years, pollution (including biocides) has become so massive and widespread that people are concerned whether any living creatures, man included, can long survive. The Breeding Bird Survey is one of several ways in which we hape to be able to monitor changes in bird populations resulting from environmental changes. Other methods used elsewhere, such as nesting studies and censuses of sample plots, require that observers restrict their activities to relatively small areas, in marked contrast to the wideranging habits of most North American bird watchers. The Breeding Bird Survey was planned with car travel and large areas in mind, and accordingly has received enthusiastic support from volunteer assistants.

The procedure used was developed in Maryland by Chandler S. Robbins of the United States Fish and Wildlife Service. It was first used in Canada in 1966, and was used in all provinces except Newfoundland in 1968 and 1969 (Table 1). Operations in Canada are under general supervision by the Canadian Wildlife Service. Each survey is based on a randomly selected starting point and direction, and each comprises 50 stops, of 3 minutes each, at one-half mile intervals along a road. Each route is surveyed once, under favourable conditions, during June, starting one-half hour before sunrise. At each stop, all birds heard and all seen within $\frac{1}{4}$ mile are listed on forms, as are data on temperature, wind, clouds or precipitation, sky, and starting and finishing times.

Year-to-year changes are compared for routes with similar coverage, that is, those with the same observer in successive years, on comparable dates, in similar weather, and adhering to the prescribed procedures. This system of rating comparability of coverage is more restrictive than that used in the United States; we are dealing with much smaller numbers of surveys, among which those that are not

Table 1. Numbers of Breeding Bird Survey routes covered in each province, 1966-1969. Duplicate coverages and non-random routes are excluded. No surveys have been made in Newfoundland in any year.

\begin{tabular}{|c|c|c|c|c|}
\hline \multirow[b]{2}{*}{ Province } & \multicolumn{4}{|c|}{ Number of routes surveyed } \\
\hline & 1966 & 1967 & 1968 & 1969 \\
\hline Prince Edward Island & 2 & 4 & 4 & 4 \\
\hline Nova Scotia .................... & 16 & 20 & 20 & 20 \\
\hline New Brunswick & 15 & 19 & 22 & 23 \\
\hline Quebec ................. & 3 & 7 & 17 & 20 \\
\hline Ontario ... & 0 & $4+\dagger$ & 41 & 40 \\
\hline Manitoba ....... & - & 11 & $12 \ddagger$ & 12 \\
\hline Saskatchewan & - & - & 3 & 6 \\
\hline Alberta & - & - & 5 & 7 \\
\hline British Columbia & - & - & 16 & 16 \\
\hline
\end{tabular}

$\dagger$ Results for a number of Ontario routes surveyed in 1967 were lost by the person then acting as provincial co-ordinator; the number of routes actually covered in that year is unknown.

$\$$ Includes one survey done from an outboard canoe, with 25 stops each on two successive mornings, around the perimeter of a large lake. 
fully comparable between years are more apt to distort the results. Analyses have been made only for reasonably uniform areas within which 15 or more (preferably 25 or more) routes received comparable coverage in successive years.

Birds Census in Britain (S. M. Taylor, 1965, Bird Study, 12:268-285), and is outlined in a more detailed publica- tion on the Breeding Bird Survey now in preparation.

The trends shown in Figure 1 suggest that the Survey will adequately detect and describe changes resulting from severe weather during future migration or breeding seasons. It should also detect changes in land use; most changes of this type will affect only a few stops on any given

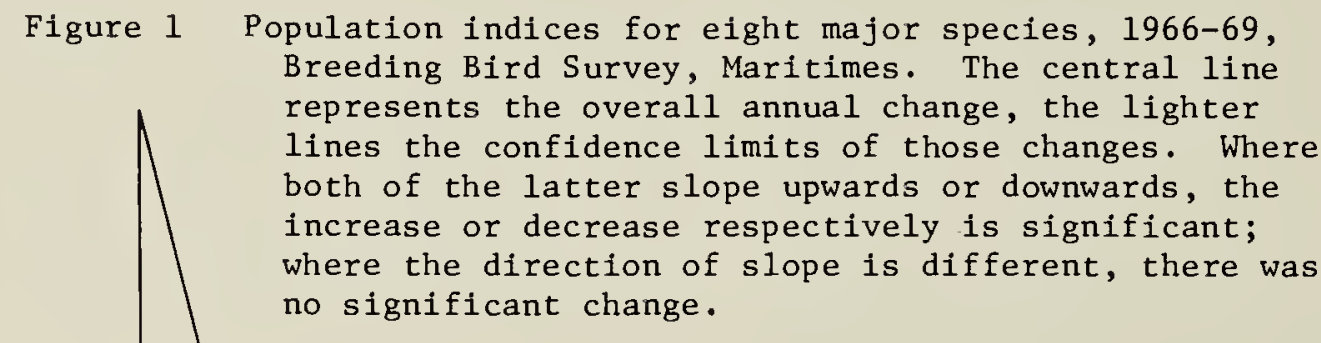
no significant change.

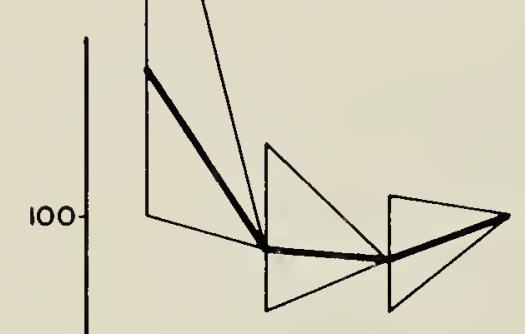

Yellow Warbler
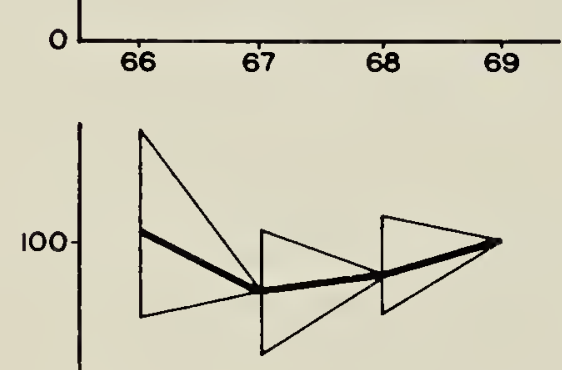

Common Crow
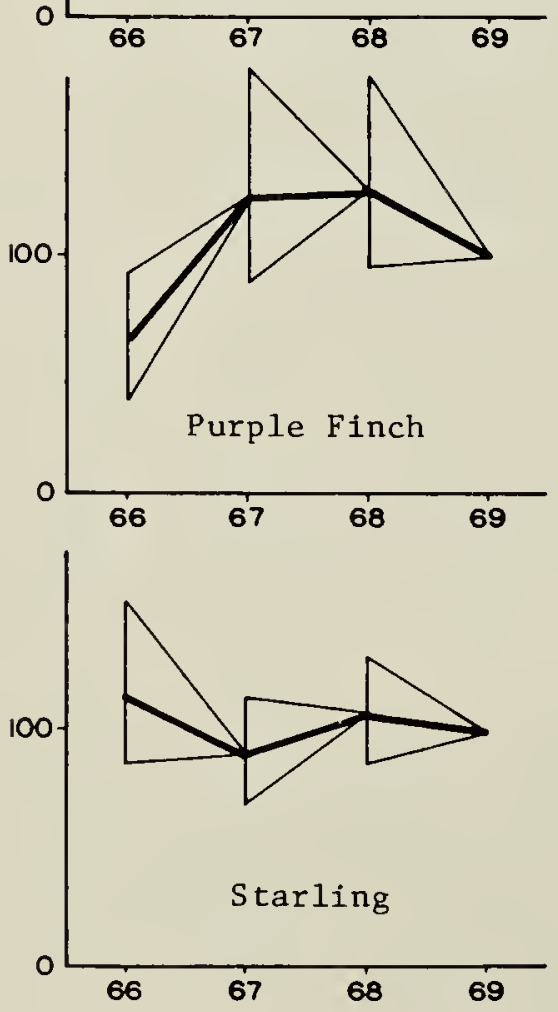
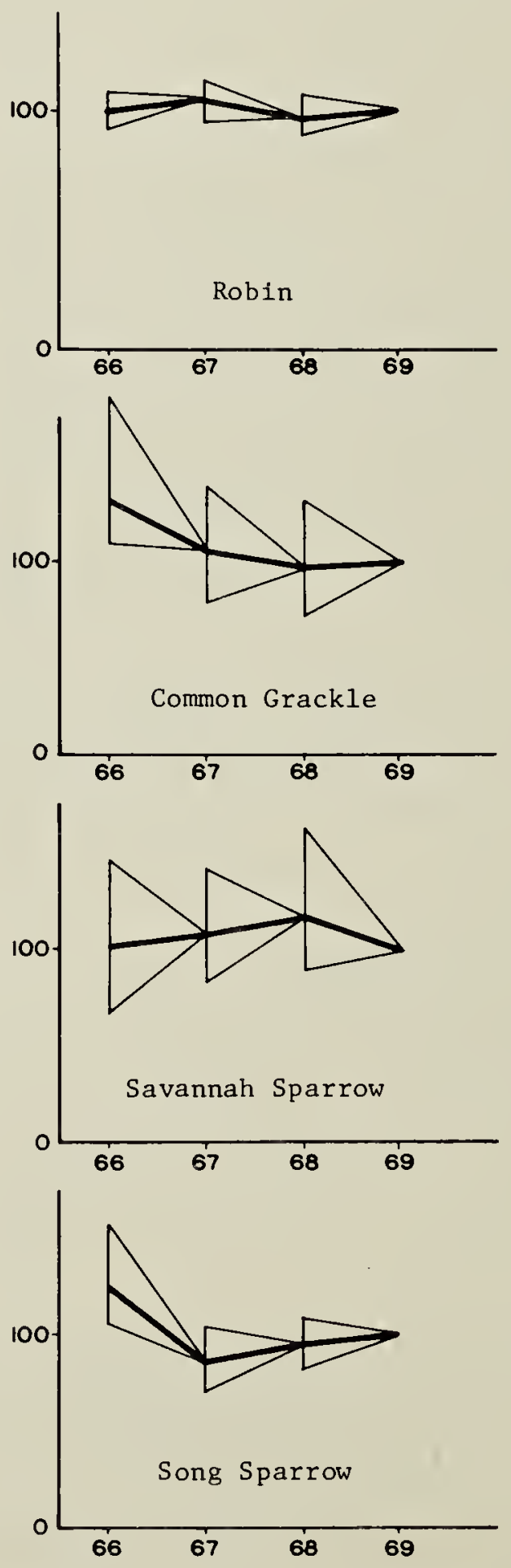
route in any one year, so the Survey will need to continue for many years before such effects are demonstrable on a province-wide scale. It remains to be seen whether the effects on birds of pollution and pesticides can be demonstrated by this procedure. As data become available, we hope to develop more sophisticated analysis methods to measure the significance of the minor but sustained changes that we tend to associate with these influences; our present methods are probably adequate to document any relatively major changes between years.

Some people will object that this is a lot of work to put into a relatively unproven method, and it certainly is. Yet we do not have the next ten years in which to work out and test this and other methods; by 1980 the effects of man-caused pollution will, if not checked, be upon us, and we will need all the data we can to show what conditions prevailed in earlier times. It is obviously unfortunate that this method was not in use earlier; most of us have impressions that certain species have decreased or increased over a period of years, but we have no satisfactory numerical data to support these beliefs. The Breeding Bird Survey is one way in which we can systematically collect data on bird numbers, and we can use more assistance than we now have.

\section{CO-OPERATIVE SPRING MIGRATION STUDY}

Records are again requested for the continent-wide survey being made under the auspices of the U.S. Fish and Wildlife Service. For a list of species studied, see Blue Jay, September 1968, Vol. 26, \#3, pp. 132-3. All records should be submitted by June 15, 1970 to:

Mrs. Mary Houston, 863 University Drive, Saskatoon, Sask.
We have not yet been able to set up analyses for routes in the Prairie Provinces. Of the 20 routes surveyed in 1968,16 were covered again in 1969 , but only 8 received comparable coverage, according to the criteria used elsewhere. We are especially anxious to increase the coverage in the prairie areas of Saskatchewan and Alberta in 1970; these areas have received far more treatment with pesticides than have the parkland and forested areas to the north, and are thus in more need of an effective monitoring system. There are about 70 degree-blocks of prairie (grassland, grain, and fallow) in the three provinces; we need about 40 routes surveyed in order to ensure that 25 receive comparable coverage from year to year.

It is not essential to be able to identify all sounds made by our native birds in order to take part in these surveys (it does help!) The important thing is to be able to correctly identify the common species, as analyses will usually be restricted to these birds. If we have to choose, we find it more helpful to have someone of average competence who can provide coverage for a number of successive years, rather than the local expert who will be birding in South America next year and in Europe two years after that. Consistent coverage is critical.

\section{PRAIRIE NEST RECORDS SCHEME}

Contributors are reminded to send 1970 nest records cards to Dr. Robert W. Nero, Prairie Nest Records Scheme, Manitoba Museum of Man and Nature, Winnipeg 2. If you have not previously contributed to the scheme but are interested in keeping records, write to Dr. Nero for information and nest record cards. Also available from him is the summary of the scheme's first 10 years operation (1958-67). 